HID 40 (2013)

\title{
PARA EL CONOCIMIENTO DE LA COSTA DE LA ANDALUCÍA ATLÁNTICA (SIGLOS XIV-XVI): DESCRIPCIONES, RELACIONES Y DOCUMENTACIÓN NÁUTICA ${ }^{1}$
}

\author{
FOR THE KNOWLEDGE OF THE ANDALUSIAN ATLANTIC COAST \\ (CENTURIES $14^{\mathrm{TH}}-16^{\mathrm{TH}}$ ): DESCRIPTIONS, RELATIONSHIP AND \\ NAUTICAL DOCUMENTATION
}

\author{
Víctor MuÑoz Gómez \\ Instituto Universitario de Estudios Medievales y Renacentistas (CEMYR) \\ Universidad de Valladolid \\ vmg1981@gmail.com
}

RESUMEN: este artículo pretende ofrecer una valoración crítica acerca de algunas de las fuentes más idóneas relativas a esta temática por lo que respecta a las costas de Andalucía atlántica durante este período. En primer lugar, los portulanos y cartas náuticas medievales. En segundo lugar, memoriales descriptivos, tratados y manuales náuticos impresos. Finalmente, aquellas fuentes literarias que dan cuenta de actividades marítimas desarrolladas a lo largo del litoral andaluz tales como expediciones diplomáticas, militares y comerciales o cualquier tipo de viaje.

Palabras Clave: Historia marítima, Corona de Castilla, Andalucía, Baja Edad Media, topografía costera, fuentes.

ABSTRACT: This paper aims to provide a critical assessment about some of the more suitable sources related to this subject for the Andalusian Atlantic coast during this period. Firstly, medieval and early modern portolan charts. Secondly, nautical accounts and printed pilot-guides. Finally, narrative sources which take into account maritime activities developed across Andalusian littoral such as diplomatic, military and commercial expeditions or any kind of journey.

KEYwords: Maritime history, Crown of Castile, Andalusia, Late Middle Ages, coastal topography, sources.

1. Este trabajo forma parte del proyecto de investigación De mar a mar. Los puertos castellanos en la Baja Edad Media (ref. HAR2010-17693), financiado por el Ministerio de Economía y Competitividad.

Abreviaturas utilizadas: $A E M=$ Anuario de Estudios Medievales; AGI = Archivo General de Indias; AGS = Archivo General de Simancas. 


\section{1.- INTRODUCCIÓN}

Desde el año 2011, el grupo de investigación Castilla y el Mar de la Universidad de La Laguna se halla empeñado en el desarrollo del proyecto de investigación De mar a mar. Los puertos castellanos en la Edad Media, financiado por el Ministerio de Economía y Competitividad. Dentro de la ya dilatada trayectoria del grupo y sus miembros en el estudio de la Historia Marítima de la Corona de Castilla en los siglos finales del Medievo $^{2}$, con este proyecto de investigación se planteaban unos objetivos bien definidos, que pueden concretarse en los siguientes puntos. Por una parte, en la ajustada valorización del influjo que los procesos de urbanización e incremento de las actividades marítimas tuvieron en la vida de los puertos del reino, en el momento que se produjo la transformación de Castilla en una gran potencia europea y en el que triunfa el traslado de actividad naval y comercial desde el Mediterráneo hacia el Atlántico, entre los siglos XIV y XVI. Por otra parte, en la consideración de la influencia que pudieron tener estos lugares portuarios en el desarrollo de los espacios adyacentes y la medición de la misma a la hora de evaluar la conformación de hinterlands interdependientes con estos centros portuarios y la propia evolución de las áreas regionales en que se hallaban integrados tales puertos. Finalmente, en el análisis de la posible existencia de redes de intercambio económico en torno a estos puertos castellanos y su representación gráfica, poniendo en relación la conexión entre ellos y sus respectivos entornos a través de los diferentes medios de transporte de la época (terrestre, fluvial y marítimo).

No obstante, en este sentido es importante atender a un aspecto sin duda relevante a la hora de comprender la articulación de tales redes portuarias y de intercambio marítimo: el estudio de la topografía costera castellana del final de la Edad Media y los inicios de la Edad Moderna. Y es que la incidencia de estos factores de orden geográfico en la práctica de la navegación en torno a aquellas costas no puede soslayarse ni tampoco la relación existente entre la actividad marinera y el nivel de conocimientos acerca de tales espacios marítimos y costeros manejado por las gentes de la época, sus formas de codificación y transmisión, etc. ${ }^{3}$.

2. En relación a la trayectoria del grupo de investigación en este sentido, una breve exposición de sus principales hitos y resultados en el portal web del mismo: http://www.castillayelmar.com/ historial-investigador/ y http://www.castillayelmar.com/proyectos-de-investigacion/ (Consultado el 14-IV-2013).

3. Esta afirmación se sostiene sobre el convencimiento de que el análisis histórico no puede desatender a la condición volitiva de la relación entre las sociedades humanas y el espacio a lo largo del tiempo. Es decir, al carácter dinámico y cambiante de esa relación, fruto de la acción continua de los grupos humanos que habitan, explotan y conciben ese espacio, organizándolo y construyéndolo como tal. Sobre el interés del historiador como científico social por el desenvolvimiento de determinadas prácticas, conceptos y discursos que se integra dentro de dinámicas más profundas de génesis social del espacio y de encuadramiento en el mismo, algunas ideas cenitales en M. DE CERTEAU. La invención de lo cotidiano. 1. Artes de hacer, México, Universidad Iberoamericana, 1996 ( $1^{\mathrm{a}}$ ed. francés, París, 1980), sobre la noción de "lugar creado" (p. 129), pero también en la formulación de "organización social del espacio" del profesor José Ángel García de Cortázar, de influencia central en la evolución historiográfica del medievalismo español en los últimos treinta años: J.Á. GARCÍA DE CORTÁZAR, 
Huelga manifestar que una aproximación crítica a las fuentes documentales potencialmente útiles para estos fines es absolutamente necesaria. Por lo que respecta al estudio del fenómeno portuario medieval en el que fue uno de los ámbitos claves en la expansión marítima de Castilla en la Baja Edad Media (política, social, económica, cultural), el de la Andalucía atlántica ${ }^{4}$, algunos de los miembros del equipo de investigación tuvimos la ocasión de proponer una valoración de aquellas fuentes documentales de carácter "público" y "privado" disponibles para el análisis de esta temática dentro del dicho marco espacio-temporal. Conservadas en archivos y bibliotecas de diferente índole y titularidad, fue posible plantear un balance del grado de descripción y edición que se ha alcanzado de muchas de ellas hasta la fecha y del tratamiento historiográfico al que han sido sometidas tales fuentes 5 .

En ese estudio también hubo lugar a apuntar algunas de las posibilidades que, para la investigación futura, abría el tratamiento de la documentación de carácter gráfico, básicamente cartografía y dibujos de la costa, hasta la fecha no suficien-

et al., Organización social del espacio en la España medieval. La Corona de Castilla en los siglos VII $a X V$, Barcelona, Ariel, 1985; J.Á. GARCÍA DE CORTÁZAR Y RUIZ DE AGUIRRE. "Organización social del espacio: propuestas de reflexión y análisis histórico de sus unidades en la España medieval", Studia Historica. Historia Medieval, 6, 1988, pp. 195-236; IDEM. "Organización del espacio, organización del poder entre el Cantábrico y el Duero en los siglos VIII a XIII”, en J.Á. GARCÍA DE CORTÁZAR Y RUIZ DE AGUIRRE. (ed.) Del Cantábrico al Duero. Trece estudios sobre organización social del espacio en los siglos VIII a XIII, Santander, Universidad de Cantabria, 1999, pp. 15-48; IDEM. Sociedad y organización del espacio en la España medieval, Granada-Valencia, Universidad de Granada-Universitat de València, 2004.

4. Dentro de la extensa bibliografía que, de un modo más o menos directo o tangencial ha atendido al factor marítimo en la evolución histórica del territorio del reino de Sevilla en la Baja Edad Media, citar aquí sólo algunos ejemplos señeros más directamente ligados a la configuración de su red portuaria, como pueden ser F. PÉREZ EMBID. "Navegación y comercio en el puerto de Sevilla en la Baja Edad Media", Anuario de Estudios Americanos, 25, 1968, pp. 43-94; M. GONZÁLEZ JIMÉNEZ. "La baja Andalucía en vísperas del descubrimiento", en Canarias y América antes del Descubrimiento. La expansión europea. VII Jornadas de Estudios Canarias-América, Santa Cruz de Tenerife, Confederación Española de Cajas de Ahorros, 1985, pp. 109-147; A.M. BERNAL RODRÍGUEZ, A. COLLANTES DE TERÁN SÁNCHEZ. "El puerto de Sevilla, de puerto fluvial medieval a centro portuario mundial (siglos XIV-XVII)", en S. CAVACCIOCHI. (ed.) I porti come impresa economica. Atti della XIX Settimana di Studio. Florencia, Le Monnier, 1988, pp. 779-824; M.Á. LADERO QUESADA. "Puertos de Andalucía durante la Baja Edad Media: Sevilla y Málaga", en E. POLEGGIO. (ed.) Città portuali del Mediterraneo. Storia e Archeologia. Atti del Convegno Internazionale di Genova, 1985. Génova, SAGEP Editrice, 1989, pp. 133-140; M. GONZÁLEZ JIMÉNEZ, J.M. BELLO LEÓN. "El puerto de Sevilla en la Baja Edad Media (siglos XIII-XV)", en D. ABULAFIA, B. GARÍ. (ed.) En las costas del Mediterráneo occidental. Las ciudades de la Península Ibérica y del reino de Mallorca y el comercio mediterráneo en la Edad Media, Barcelona, Omega, 1996, pp. 213-271; E. AZNAR VALLEJO. "Cádiz y su región en la expansión atlántica", Estudios de Historia y Arqueología medievales, 10, 1994, pp. 11-23; A. COLLANTES DE TERÁN SÁNCHEZ. "Papel del Atlántico en la configuración de Andalucía", Historia. Instituciones. Documentos, 35, 2008, pp. 85-105; J.M. BELLO LEÓN, A. MARTÍN PERERA. Las atarazanas de Sevilla a fines de la Edad Media, Murcia, Editum. Ediciones de la Universidad de Murcia, 2012.

5. J.M. BELLO LEÓN, V. GÓMEZ, R.J. GONZÁLEZ ZALACAIN. "Nuevas propuestas con viejas fuentes: la documentación para el estudio de los puertos andaluces en la Época de los Descubrimientos", en XX Coloquio de Historia Canario-Americana, Cabildo de Gran Canaria-Casa de Colón, Las Palmas de Gran Canaria (en prensa). 
temente considerados en el estudio de la Historia marítima de la baja Andalucía medieval. En el presente trabajo mi intención es volver sobre la cuestión de las fuentes por lo que se refiere a la cuestión que señalaba del conocimiento topográfico de las costas atlánticas andaluzas entre los siglos XIV y XVI, la descripción de sus accidentes geográficos terrestres y marinos y de sus lugares portuarios, entre las que, precisamente, las fuentes cartográficas tienen un lugar extraordinariamente relevante. Consideraremos, pues, una evaluación de algunas de las fuentes más idóneas para la aproximación al espacio geográfico marítimo andaluz bajomedieval y sus condiciones de navegación, ligadas a dinámicas estratégico-militares y mercantiles, y a las perspectivas de análisis historiográfico que suscitan. Muy concretamente, me estoy refiriendo a tres bloques heterogéneos de fuentes que serán tratados en las páginas siguientes. Primeramente, la documentación gráfica náutica por excelencia, cartas náuticas y portulanos. Seguidamente, los casos de derroteros y tratados y memoriales descriptivos de los ámbitos costeros andaluces. Finalmente, los casos de narraciones literarias de la época en las que se refieren viajes y acciones navales en la zona de interés en este estudio.

\section{2.- CARTOGRAFÍA MEDIEVAL: CARTAS NÁUTICAS Y PORTULANOS}

En general, la atención dedicada al estudio de la documentación náutica medieval ha tenido una nada desdeñable tradición entre la historiografía occidental ${ }^{6}$. La cartografía medieval se ha mostrado como una valiosa fuente para la reconstrucción de la imagen de los espacios costeros del Mediterráneo y, globalmente, del Occidente bajomedieval ${ }^{7}$, si bien los estudiosos no han dejado de evidenciar los problemas aparejados a la interpretación de los conocimientos geográficos manejados para la práctica náutica de los últimos siglos de la Edad Media a partir de tales fuentes cartográficas.

Esas dificultades tienen que ver, por una parte, con la propia correspondencia de la mayoría de las cartas náuticas que han llegado hasta nosotros más como documentos "de gabinete", con funcionalidad diplomática o científica, que como los auténticos instrumentos manejados en la práctica de la navegación por maestres

6. Algunos títulos significativos a este respecto y para un estado de la cuestión, vid. M. DE LA RONCIÈRE, M. MOLLAT DU JOURDIN. (eds.) Les portulans. Cartes marines du XIIIe. au XVIIe. siècle, Fribourg en Nuithonie, (Suiza), Office du Livre, 1984; F. MELIS, "Elenco descrittivo dei porti dell'Europa in un manoscritto fiorentino della fine del Trecento", en L. FRANGIONI. (ed.) I trasporti e le comunicazioni nel Medioevo, Florencia, Le Monnnier, 1984, pp. 69-76; T. CAMPBELL, "19. Portolan Charts from the Late Thirteenth Century to 1500", en J.B. HARLEY, D. WOODWARD. (eds.) The history of cartography. I. Cartography in prehistoric, ancient and medieval Europe and Mediterranean, Chicago-Londres, University of Chicago Press, 1987, pp. 371-463; P. GAULTIER DALCHÉ. "Cartes marines, représentation du littoral et perception de l'espace au Moyen Âge. Un état de la question”, en J.-M. MARTIN. (ed.) Castrum 7. Zones côtières littorales dans le monde méditerranéen au moyen âge: défense, peuplement, mise en valeur, Madrid, Casa de Velázquez, 2001.

7. Buen ejemplo de ello puede ser el estudio comparativo entre Cataluña y la Toscana de S. ORVIETANI BUSCH. Medieval mediterranean ports: the Catalan and Tuscan coasts, 1100 to 1235 , Leiden, Brill, 2001. 
y patrones de naves en aquella época ${ }^{8}$. Por la otra, y teniendo en cuenta el factor anteriormente señalado, los mismos procedimientos de tratamiento de los datos geográficos recogidos en ellas y de transmisión de los conocimientos actualizados a lo largo del tiempo acerca del mar, de las costas, de sus accidentes geográficos y de los puertos, fondeaderos y poblaciones relevantes en ellas. De hecho, la elaboración a lo largo de la Baja Edad Media de muchas de estas cartas a partir de modelos anteriores con criterios de habitual respeto a la tradición y el conocimiento erudito recibidos ha dado lugar a que se observe en ellas una tendencia a una lenta incorporación de datos útiles para el apoyo de la actividad náutica pero, al tiempo, a la fosilización de noticias y referencias a veces desfasadas y en otros casos más propias de un imaginario mítico de lo maravilloso muy característico, por otro lado, de la cultura medieval occidental ${ }^{9}$.

Aun considerando que la dinámica de incorporación y corrección de informaciones eminentemente prácticas para la navegación en estas cartas a partir del siglo XV podía extenderse durante varias décadas - un tiempo que, por otro lado, no parece excesivamente largo al pensar en la difusión del conocimiento medieval- ${ }^{10}$, nada de ello reduce, en cualquier caso, el interés del recurso a cartas y portulanos para el estudio del espacio geográfico marítimo, físico y humano, de la Europa medieval. Es más, se trata de una fuente de primer orden para comprender los efectos y los tiempos de la difusión de estos conocimientos y la integración de los mismos por parte los miembros de las sociedades medievales directamente implicados en actividades relacionadas con el mar y la navegación.

Con todo, el recurso a estas fuentes para el estudio del ámbito costero de la Andalucía atlántica ha sido bastante discreto hasta la fecha, pudiendo contrastarse con el mucho más intensivo aplicado al caso de las costas del reino nazarí de Granada. En este sentido, pueden citarse los artículos de Carlos Gozalbes Cravioto, centrado en el área del estrecho de Gibraltar, a partir de hasta veintitrés portulanos datados entre los inicios del siglo XIV y el año $1501^{11}$, y el dedicado por Raúl

8. U. TUCCI, "La carta nautica", en S. BIADENE. (ed.) Carte da navigar. Portolani e carte nautiche del Museo Correr 1318-1732, Venecia, Marsilio, 1990, pp. 9-19; P. GAULTIER DALCHÉ. "L'usage de cartes marines aux XIV . et XV'. siècles", en Spazi, tempi, misure e percorsi nell'Europa del Basso Medioevo. Atti del XXXII Convegno storico internazionale. Todi, 8-11 ottobre 1995, Spoleto, Centro Italiano di Studi sull'Alto Medioevo, 1996, pp. 97-128.

9. Algunas referencias a este respecto en F. MELIS. "Elenco descrittivo..."; U. TUCCI. "La carta nautica"; S. GENSINI. (ed.) Europa e Mediterraneo tra Medioevo e prima età moderna: l'osservatorio italiano, Pisa, Centro di Studi sulla Civiltà del Tardo Medioevo, 1992; A-D. VON DEN BRINCKEN. "Mappe del cielo e della terra: l'orientamento nel basso medioevo", en Spazi, tempi, misure..., pp. 8196, p. 82; G. PETTI BALBI. "Distanze e programmi di viaggio sul mare" en Spazi, tempi, misure..., pp. 271-295. Para un acercamiento al choque entre la conciencia mitológica y la progresiva construcción del conocimiento práctico del espacio oceánico atlántico por parte de la sociedad feudal occidental del Medievo, E. AZNAR VALLEJO. "Del mar soñado al mar hollado. El redescubrimiento del Océano", Cuadernos del Cemyr, 15, 2007, pp. 175-195.

10. R. GONZÁLEZ ARÉVALO. "La costa del Reino de Granada en la documentación náutica italiana (siglos XIV-XVI)", En la España medieval, 31, 2008, pp. 7-36, en concreto pp. 14-15.

11. C. GOZALBES CRAVIOTO. "La costa del campo de Gibraltar en los portulanos medievales", Almoraima. Revista de estudios campogibraltareños, 13, 1995, pp. 163-174; IDEM. "Tarifa en la geografía medieval. Fuentes textuales (I)", Aljaranda. Revista de estudios tarifeños, 54, 2004, pp. 7-12; 
González Arévalo al conjunto de la costa del reino de Sevilla, basándose en el análisis de documentación náutica florentina fechada entre el final del siglo XIII y mediados del siglo XVI - un total de siete cartas, además del conocido Compasso a mostrare a navicare de Uzzano ${ }^{12}$ - Sus conclusiones resultan ciertamente interesantes, al precisar hasta diez hitos geográficos en la costa que media entre el río Guadiana y Gibraltar: la roca Salmedina, citada normalmente como Medina -baja frente a Chipiona en el acceso hacia la barra de Sanlúcar, reconocida como de gran peligro para la navegación y que, en la documentación náutica medieval se interpretaba, con cierto fundamento, como los restos de una antigua ciudad ${ }^{13}$-, los cabos de Trafalgar y del Carnero y hasta ocho puertos y fondeaderos, a saber Sanlúcar de Barrameda, Sevilla, El Puerto de Santa María, Cádiz, Tarifa, Algeciras y Gibraltar. Estos datos dan una cierta idea sobre una presumible jerarquía de los puertos y accidentes geográficos de la zona considerados por los navegantes que participaban en las grandes rutas marítimas a grande distancia y su puesta en relación con otras grandes etapas del comercio italiano en el ámbito ibérico, norteafricano y hacia el Atlántico ${ }^{14}$.

IDEM. "Tarifa en la geografía medieval. Las fuentes cartográficas (y II)", Aljaranda. Revista de estudios tarifeños, 55, 2004, pp. 5-10.

12. R. GONZÁLEZ ARÉVALO, "La costa del reino de Sevilla en la documentación náutica italiana (siglo XV)", en A. MALPICA CUELLO, R.G. PEINADO SANTAELLA, A. FÁBREGAS GARCÍA. (eds.) Historia de Andalucía. VII Coloquio, Granada, Universidad de Granada, 2010, CDComunicaciones, pp. 301-317. El Compasso a mostrare a navicare dall'uno stretto all'altro, incluido dentro de la Prattica de la Mercatura de Giovanni di Antonio da Uzanno, redactado en 1442 [G. PAGNINI DEL VENTURA. Della decima e di varie altre gravezze imposte dal Comune di Firenze. Della moneta e della Mercatura de fiorentini fino al secolo XVI, vol. IV: Contenente la Pratica della Mercatura scritta da Giovanni di Antonio da Uzzano (nel 1442), Lisboa-Lucca, 1766 (ed. facsímil, Bolonia, Forni Ed., 1967, Vol. II, pp. 199-276)], es una fuente fundamental para el estudio de las rutas de navegación italianas del final de la Edad Media y que ha sido manejado en múltiples estudios, entre los que, para los intereses de este trabajo en relación a la descripción de los espacios costeros ibéricos, merece la pena citar el de D. IGUAL LUIS. "Itinerarios comerciales en el espacio meridional mediterráneo de la Baja Edad Media", en Itinerarios medievales e identidad hispánica: XXVII Semana de Estudios Medievales, Estella 17 a 21 de julio de 2000, Pamplona, Gobierno de Navarra, Dpto. de Educación y Cultura, 2001, pp. 113-158.

13. Autores grecolatinos como Estrabón, Pomponio Mela y Avieno citan la presencia de una población y un faro de fundación romana en lo que debió de ser una isla, luego anegada por el avance del mar, en lo que es la Roca Salmedina. Los hallazgos arqueológicos púnicos y romanos realizados desde el siglo XIX en ese lugar confirman la existencia de un antiguo asentamiento. Vid. J. MAIER, J. SALAS. Comisión de Antigüedades de la Real Academia de la Historia. Andalucia. Catálogo e indices, Madrid, Real Academia de la Historia, 2000, pp. 103, 127; A. SCHULTEN. Tartessos. Contribución a la Historia más antigua de Occidente, Sevilla, Almuzara, 2006, pp. 204-205.

14. En esta línea de aportaciones, habrá que tener en cuenta la ponencia recientemente presentada por la investigadora francesa E. VAGNON con el título "Le détroit de Gibraltar dans les cartes marines européennes du XVe et XVI ${ }^{e}$ siècle: toponymie et iconographie", en el marco del coloquio Estrechos. encontradas sobre la imagen del Estrecho de Gibraltar (Antigüedad y Edad Media), celebrado en la Casa de Velázquez (Madrid) los días 11 y 12 de abril de 2013. La publicación surgida de esta reunión científica puede ser de gran interés en la contribución al tema que nos ocupa en estas páginas. Más información al respecto en http://www.casadevelazquez.org/es/investigacion/novedad/estrechos/ (consultado 2-II-2013). 
Sea como fuere, el análisis en profundidad de esta documentación cartográfica queda en gran medida por hacer y pasa por la ampliación del corpus al que se recurra para la descripción de estas costas atlánticas andaluzas, cuando menos para la ampliación del elenco de hitos nombrados en los litorales onubense y gaditano, como ya apunta González Arévalo ${ }^{15}$. Esta es una tarea que ha quedado muy allanada para el investigador gracias a la disponibilidad bien a partir de su edición, bien en formato digital a través de los portales web de archivos y biblioteca de decenas de cartas náuticas datadas entre los siglos XIV-XVI ${ }^{16}$. El despliegue de una metodología rigurosa para el tratamiento de las denominaciones de los puntos geográficos citados en los portulanos y de las formas gráficas en que son representados en ellos puede aportar interesantes luces a la hora de esbozar una jerarquía dentro de la red portuaria del reino de Sevilla y su evolución a lo largo del tiempo, basada tanto en la relevancia de estas localidades en su condición de centros comerciales como en las cualidades navales de estos lugares para el refugio, fondeo, carga y descarga de naves. Los estudios, mucho más desarrollados, en esta dirección para la costa del reino de Granada ${ }^{17}$, muestran un camino a seguir. Así, la combinación de estas informaciones cartográficas con las extraídas de fuentes escritas, muy

15. R. GONZÁLEZ ARÉVALO. "La costa del reino de Sevilla...", p. 304.

16. Si Campbell estimaba a final de los años ochenta del siglo XX el total de cartas náuticas y portulanos fechados entre el final del siglo XIII y el comienzo del siglo XVI conservadas en torno a los ciento ochenta ejemplares (T. CAMPBELL. "19. Portolan Charts...", p. 371), de particular relevancia resulta la magna obra de R.J. PUJADES I BATALLER. Les Cartes portolanes. La representació medieval d'una mar solcada, Barcelona, Institut d'Estudis Catalans-Institut Cartogràfic de CatalunyaInstitut Europeu de la Mediterrània-Lunwerg, 2007. En ella, además del brillante estudio realizado acerca de esta cartografía medieval, se ponen a disposición del investigador en formato digital hasta 129 cartas náuticas y atlas datados entre el final del siglo XIII y 1470 a partir de imágenes de alta calidad. Algunos buenos ejemplos, por otra parte, de archivos y bibliotecas que, a través de sus portales web permiten el acceso a sus fondos cartográficos medievales, ofreciendo imágenes de los mismos de calidad muy variable, pueden ser los de la Biblioteca Nacional de Francia a través del sitio Gallica (http://gallica.bnf.fr) o la Beinecke Rare Book\&Manuscript Library de la Universidad de Yale (http:// beinecke.library.yale.edu/collections/highlights/portolan-charts; consultado 18-IV-2013), entre otros posibles. Merece la pena recordar aquí el proyecto desarrollado entre 1995 y 2000 por el Museo de Historia de Tenerife Portulanos del Mundo. Desde la Antigüedad al siglo XV y que se concretó en la publicación en formato CD-ROM de un total de noventa y dos cartas y atlas de entre finales del siglo XIII y los comienzos del siglo XVI. No obstante, la baja calidad de muchas de las imágenes recopiladas rebaja considerablemente la utilidad científica de buena parte del corpus cartográfico ahí reunido.

17. C. GOZALBES CRAVIOTO. "La frontera oriental nazarí en los portulanos medievales", en P. SEGURA ARTERO. (coord.) Actas del Congreso La frontera oriental nazarí como sujeto histórico (S. XIII-XVI). Lorca-Vera, 22 a 24 de noviembre de 1994, Almería, Instituto de Estudios AlmeriensesDiputación de Almería, 1997, pp. 451-466; IDEM. "La frontera terrestre nazarí en la cartografía medieval”, en F. TORO CEBALLOS, J. RODRÍGUEZ MOLINA. (ed.) II Estudios de Frontera. Actividad y vida en la Frontera. En memoria de don Claudio Sánchez-Albornoz. Congreso celebrado en Alcalá la Real, del 19 al 22 de noviembre de 1997, Jaén, Diputación Provincial de Jaén, 1998, pp. 357-370; IDEM. "La frontera marítima del occidente malagueño en los documentos geográficos medievales cristianos", en F. TORO CEBALLOS, J. RODRÍGUEZ MOLINA. (ed.) IV Estudios de Frontera. Historia, tradiciones y leyendas en la frontera. Homenaje a Don Enrique Toral y Peñaranda. Congreso celebrado en Alcalá la Real en noviembre de 2001, Jaén, Diputación Provincial de Jaén, 2002, pp. 247-265; IDEM. "La costa granadina en la cartografía medieval", Qalat. Revista de historia y patrimonio de Motril y la costa de Granada, 4, 2004, pp. 115-129; R. GONZÁLEZ ARÉVALO. "La costa del Reino de Granada...". 
especialmente notariales y privadas de tipo mercantil generadas por los mercaderes de origen italiano que operaban en el sultanato nazari ${ }^{18}$, pero también con los resultados obtenidos de la interpretación de los registros arqueológicos en zonas costeras granadinas ${ }^{19}$, está dando notables frutos. Ello permite hablar de una sobresaliente ampliación del conocimiento del ámbito costero granadino islámico y de las sinergias económicas y sociales en él se experimentaron durante los últimos siglos del Medievo ${ }^{20}$. En esta línea se conducen algunos de los esfuerzos del proyecto De mar a mar y, precisamente, esa vía de estudio de la cartografía histórica

18. Sin ánimo de ser exhaustivo, algunos títulos particularmente relevantes de esta tendencia pueden resultar los de B. GARÍ. "La advertencia del fin. Génova y el reino de Granada a mediados del siglo XV”, en A. BOSCOLO, J.J. HERNÁNDEZ PALOMO. (ed.) Presencia italiana en Andalucía. Siglos XIV-XVII. Actas del III Coloquio Hispano-Italiano, Sevilla, Consiglio Nazionale delle Ricerche-Consejo Superior de Investigaciones Científicas (CSIC)-Escuela de Estudios Hispanoamericanos, 1989, p. 179-190; B. GARÍ, R. SALICRÚ I LLUCH. "Las ciudades del triángulo: Granada, Málaga y Almería, y el comercio mediterráneo en la Edad Media”, en D. ABULAFIA, B. GARÍ. (ed.) En las costas del Mediterráneo occidental..., pp. 171-211; A. FÁBREGAS GARCÍA. "Estrategias de los mercaderes toscanos y genoveses en el Reino de Granada a través de la correspondencia Datini”, Serta Antiqua et Mediaevalia. V Società e Istituzioni del Medioevo Ligure, Roma, Giorgio Bretschneider Editore, 2001, pp. 259-403; J.E. LÓPEZ DE COCA CASTAÑER. "Granada y la ruta de Poniente. E1 tráfico de frutos secos", en A. MALPICA CUELLO. (ed.) Navegación marítima del Mediterráneo al Atlántico, Granada, Universidad de Granada-Grupo de investigación "Toponimia, Historia y Arqueología del Reino de Granada", 2001, pp. 151-177; A. FÁBREGAS GARCÍA. "Redes de comercio y articulación portuaria del Reino de Granada: puertos y escalas en el tráfico marítimo bajomedieval", Chronica Nova, 30, 2003-2004, pp. 69-102; A. GARCÍA PORRAS, FÁBREGAS GARCÍA. “Genoese trade network in the southern Iberian peninsula: trade, transmission of technical knowledge and economic interactions", Mediterranean Historical Review, 25/1, 2010, 35-51; R. GONZÁLEZ ARÉVALO. "Las galeras mercantiles de Florencia en el Reino de Granada en el siglo XV", AEM, 41/1, 2011, pp. 125-149; IDEM. “Apuntes para una relación velada: la República de Florencia y el Reino de Granada en la Baja Edad Media”, Investigaciones de Historia Económica, 8, 2012, pp. 83-93.

19. A. MALPICA CUELLO, A. GÓMEZ BECERRA. "La formación de un territorio fronterizo medieval: la costa granadina de la época musulmana a la conquista castellana", en Fronteras. III Coloquio de Arqueología Espacial, Teruel, Colegio Universitario de Teruel. Seminario de Arqueología y Etnografía turolenses, 1989, pp. 241-255; IDEM. "El poblamiento medieval de la costa oriental granadina", en Actas del III Congreso de Arqueología Medieval Española. Tomo II Comunicaciones, Oviedo, Universidad de Oviedo, 1992, pp. 313-319; A. MALPICA CUELLO. "Il traffico commerciale nel mondo mediterraneo occidentale alla fine del Medioevo: il Regno di Granada”, en P. ALBERINI. (ed.) Aspetti ed attualità del potere marittimo nel Mediterraneo nei secoli XII-XVI. Acta del Convegno di Storia Militare tenuto a Napoli, in Castel dell'Ovo, dal 27 al 29 ottobre 1997, Roma, Ufficio Storico della Marina Militare - Commissione Italiana di Storia Militare, 1999, pp. 351-381; A. MALPICA CUELLO, A. FÁBREGAS GARCÍA. "La vida marítima y el poblamiento medieval de la costa del Mediterráneo andaluz”, en A. MALPICA CUELLO. (ed.) Navegación marítima..., pp. 97-148; A. MALPICA CUELLO, "Poblamiento y vida marítima en el reino de Granada: la pesca y la navegación”, en V. D'ARIENZO, B. DA SELVA. (eds.) Pesci, barche, pescatori nell'area mediterranea dal Medioevo all'Età Contemporanea, Milán, Franco Angeli, 2010, pp. 53-67.

20. Una muestra muy actualizado de tal estado de la investigación histórica en torno a la costa del sultanato nazarí, capitalizada por el Grupo de Investigación "Toponimia, Historia y Arqueología del Reino de Granada", de la Universidad de Granada, en A. MALPICA CUELLO, A. FÁBREGAS. GARCÍA. "Embarcaderos y puertos en la costa del reino de Granada", en A. FÁBREGAS GARCÍA (ed.) Navegación y puertos en época medieval y moderna, Granada, Grupo de investigación “Toponimia, Historia y Arqueología del Reino de Granada", 2012, pp. 75-109. 
medieval para las riberas atlánticas de Andalucía está siendo en estos momentos explorada.

\section{3.- LA DESCRIPCIÓN DE LA COSTA: DERROTEROS Y MEMORIALES}

Otro bloque de fuentes gran importancia en lo que se refiere al conocimiento de la geografía costera y marítima andaluza es el relativo a aquellos documentos que ofrecen relaciones descriptivas más o menos detalladas de los puertos, surgideros y accidentes físicos del litoral. Uno de sus principales atractivos radica en la inclusión, junto con estos datos, de otros de más particular interés para la singladura por estas costas y cuya obtención por sus autores fue el fruto de la recopilación de experiencias prácticas en el ejercicio de la navegación por ellas, bien de forma directa por parte de aquéllos, bien a causa de su transmisión por parte de marinos veteranos en esos mares. Es el caso de las distancias calculadas entre los puntos descritos en tales relaciones, los regímenes de vientos y corrientes activos en las costas y en las entradas de los puertos, las calidades estimadas de los fondeaderos, las características de los fondos marinos o la presencia de escollos, bajíos y de otros peligros para la integridad de los navíos que operasen en esos litorales. Ese carácter eminentemente técnico y práctico induce a que sus informaciones hayan de ser tenidas muy en cuenta como testimonios veraces del estado de conocimietos resultante al final de la Edad Media del estado de las costas andaluzas y de las condiciones con que se afrontaba la navegación por ellas.

Ha de reconocerse que, por lo que respecta al ámbito andaluz, apenas han llegado hasta nosotros documentos castellanos de estas características. Afortunadamente podemos citar al menos tres, datados ya en el siglo XVI. Su contenido permite ponerlos en relación con la tratadista hispana de materia náutica e hidrográfica aparecida desde este siglo, como es el caso de la Suma de Geographia de Martín Fernández de Enciso (1519) o la Hydrografia de Andrés de Poza (1585) ${ }^{21}$, pero no tanto por la detección de influencias no corroboradas en los autores de estos documentos a partir la lectura de determinadas obras impresas de esta naturaleza. Más bien lo que puede observarse es su integración en una dinámica común de tradiciones y conocimientos marineros que hundían sus raíces en la Edad Media y que estaban cristalizando, normalizándose y transmitiéndose en forma escrita a partir del Renacimiento en España. Propiamente, en un contexto político, social, económico y cultural dominado por el desarrollo de poderes monárquicos estata-

21. El proyecto Dicter 2.0, coordinado desde el Centro de Investigaciones Lingüísticas de la Universidad de Salamanca para la elaboración del Diccionario de la Ciencia y la Técnica del Renacimiento español, ha reunido en su portal web un total de setenta y cuatro tratados científico-técnicos elaborados a lo largo del siglo XVI y el primer cuarto del siglo XVII y clasificados en doce áreas temáticas, todos ellos consultables en versión digital. Entre ellos, se consideran, dentro de las áreas de Cosmografía y Geografía y de Náutica y Arquitectura Naval, hasta catorce textos, entre ellos los arriba citados. Para mayor información acerca del proyecto, de la literatura náutica hispana de la Alta Edad Moderna y de estas obras, véase http://dicter.eusal.es/ (consultado 8-IV-2013). 
listas de raíz autoritaria y por el escenario de expansión, conquista y colonización protagonizado por la Corona de Castilla hacia el Atlántica y, en último término, hacia las Indias Occidentales, a caballo entre el Medievo y la Modernidad²2.

Precisamente, es la iniciativa de las autoridades de la Corona por recabar este tipo de informaciones acerca de las costas de la monarquía de España lo que se halla detrás de la elaboración de los memoriales que he apuntado. No me detendré en el primero de ellos, confeccionado a finales de 1526 a instancias del veedor de la gente de guerra del reino de Granada, Ramiro Núñez de Guzmán, y en el que se ofrece descripción de las costas mediterráneas de Castilla, incluido el reino de Granada, entre el cabo de Palos y Gibraltar ${ }^{23}$, para concentrarme en los otros dos, que tocan al litoral atlántico andaluz.

El primero de ellos se puede datar poco después de 1554 y, por su contenido, puede deducirse que fue redactado por el patrón o el piloto de una de las naos que participó en el socorro de las tropas del emperador Carlos V comandado por Alonso Luis de Lugo, tercer adelantado mayor de Canarias, a la ciudad de Calvi, en Córcega, sitiada por los franceses y $\operatorname{los} \operatorname{turcos}{ }^{24}$. Se presenta como una Relaçión de los puertos y cauos de la costa de España desde el cauo de Ysuer en Fuenterrauía al estrecho de Gibraltar y adelante, pero recoge datos en este sentido correspondientes a toda la Península Ibérica y a todo el Mediterráneo occidental, comprendiendo también las costas del sur de Francia, las de la Península Itálica

22. Un acercamiento actualizado al fenómeno de la expansión atlántica europea bajomedieval y altomoderna desde la óptica hispana en J.R. DÍAZ DE DURANA ORTIZ DE URBINA, J.A. MUNITA LOINAZ. (ed.) La apertura de Europa al mundo atlántico. Espacios de poder, economía maritima y circulación cultural, Bilbao, Universidad del País Vasco. Servicio Editorial/Euskal Herriko Unibertsitatea. Argitarapen Zerbitzua, 2011.

23. AGS, Cámara de Castilla. Diversos, C $.44, n^{\circ}$. 15. La relación recogida en este interesante documento puede ser contrastada con otros documentos contemporáneos expresivos de la importancia concedida a determinados puntos costeros granadinos, a razón del establecimiento de guardas para su vigilancia y defensa. Vid. AGS, Cámara de Castilla. Diversos, Ca . 44; AGS, Cámara de Castilla, Libros de Cédulas, nº. 27, ff. 33v.-55v., editado en P. ARROYAL ESPIGARES, E. CRUCES BLANCO, $M^{\mathrm{a}}$.T. MARTÍN PALMA. Cedulario del reino de Granada (1511-1514), Málaga, Universidad de Málaga, 2008, pp. 91-119, citado en A. MALPICA CUELLO, A. FÁBREGAS GARCÍA. "Embarcaderos y puertos...”, pp. 89-92).

24. Las noticias respecto a la intervención del adelantado Alonso Luis de Lugo en Córcega son bien conocidas (vid. C. FERNÁNDEZ DURO. Armada española desde la unión de los reinos de Castilla y de León, 9 Vols., Madrid, Estudio tipográfico Sucesores de Rivadeneyra, 1895-1903, Vol. I, p. 290). A partir de la mención que se hace en el documento al socorro de Calvi [“Calui, que se defendió de la armada del Turco e Françia e yo entré con socorro de gente $<$ con $>$ vna nao ynfanta de España, ano de 54". (vid. nota 25)], se intentó sondear la posible identidad del autor de la relación, en caso de que pudiera tratarse del mismo adelantado o de alguno de los oficiales de la flota que hizo el transporte a Córcega. Un primer acercamiento a la documentación simanquina sobre esta acción de armas no ha dado resultados positivos, no habiéndose localizado nexo entre este memorial y el adelantado de Canarias (AGS, Catálogo de Diversos, $n^{\circ} .1 .206,1.221$ ) ni tampoco noticias sobre la intervención de una nao ynfanta de España entre algunas de las que sí se han podido documentar empeñadas en el transporte de tropas a Calvi (AGS, Estado España, leg. 104; Estado Génova, leg. 1.383, ff. 263-264). Tal vez una investigación más profunda en los papeles del Consejo de Estado en Simancas y en el Archivo Histórico Nacional pueda dar mejores frutos. Quiero, en todo caso, agradecer a Patricia Rodríguez Rebollo, investigadora y amiga, su ayuda y orientación acerca de estos fondos en relación con este asunto. 
bañadas por el mar Tirreno y las del norte de África entre Ceuta y Túnez, además de las de las islas y archipiélagos que se encuentran en esta cuenca ${ }^{25}$. Todo indica que esta memoria fue requerida a instancias de alguno de los consejos principales de la monarquía española -Estado o Guerra, presumiblemente- como una información técnica necesaria para la protección de los intereses estratégicos marítimos de la Corona en esa zona del Mediterráneo. Así, recoge los principales puertos y surgideros en todo este espacio, las derrotas para la navegación entre ellos, considerando las direcciones de los vientos, y las distancias en leguas que separaban a los lugares portuarios, fondeaderos y accidentes geográficos más significativos correspondientes a tales derrotas. Para ello, su autor declara que la relación es el fruto de su propia experiencia náutica en estas costas, levantada sin el concurso de cartas ni libros de derrota, asumiendo las posibles inexactitudes menores en la medición de las distancias y de los rumbos a seguir o el olvido a la hora de consignar alguno de los lugares marítimos del litoral descrito ${ }^{26}$.

Aunque el nivel de detalle de las noticias que esta relación nos ofrece es más detallado para el Mediterráneo que para las costas atlánticas ibéricas, no resultan desdeñables las referencias acerca del litoral entre el cabo de San Vicente y el estrecho de Gibraltar, centrando su atención en las distancias y rumbos desde el cabo citado hacia el cabo de Santa María, en la costa portuguesa, Sanlúcar de Barrameda, Cádiz y Gibraltar ${ }^{27}$. De todos modos, su información es bastante menos rica que la aportada, años antes, en 1519, por Martín Fernández de Enciso en su Suma de Geographia, donde se recogen un mayor número de puertos -de sureste a noroeste, Gibraltar y la punta de Tarifa, Cádiz, El Puerto de Santa María, Sanlúcar, Sevilla, Saltés en la ría de Huelva, Lepe, Tavira ya en Portugal pasado el río Guadiana-y datos más precisos acerca del cálculo de distancias entre puntos de la costa, de su latitud y de sus características físicas ${ }^{28}$. Con todo, estamos ante un testimonio sobresaliente de las prácticas marineras de la época, que pueden ponerse en relación con la acumulación de saberes en el cabotaje de las costas peninsulares entre el final de la Edad Media y los inicios de la Edad Moderna.

Por lo que toca al segundo de estos memoriales, es poco más tardío, algo posterior a 1555, al referir en su relación el desastre sufrido por la flota de la carrera de Indias, capitaneada por Cosme Rodríguez Farfán, en el golfo de Cádiz, al desperdigarse el convoy en el tornaviaje desde América a causa de una tempestad

25. AGI, Indiferente General, $C^{\mathrm{a}} \cdot 1.528, \mathrm{n}^{\mathrm{o}} 39$.

26. Así, concluye el autor su relación diciendo: "Esta relación se a echo a discreción y la memoria del honbre es holbidadizo, y avn que todas las partes q<ue $>$ aquí ago memoria, /andado e estado/, por aber escripto sin carta de marear ni libros de derrotas y legoas de vna punta a otra podría ser lo errase en alguna parte en las leguas i vn cuarto de viento a vna parte o a otra, y otras que por no tener en memoria se dexan escriuir lugares de la marina y legoas; la falta V. S. perdone.” (Ibidem, f. 3v)

27. Ibidem, ff. $1 \mathrm{r}-\mathrm{v}$.

28. M. FERNÁNDEZ DE ENCISO. Suma de Geographia que trata de todas las partidas e provincias del mundo: en especial de las Indias. E trata largamente del arte de marear. Juntamente con la esfera en romance: con el regimiento del sol e del norte, Sevilla, Jacobo Cromberger, 1519, ff. XXVv-XXVIr, XXXv. Para la descripción del conjunto de las costas de la Península Ibérica, ibidem, ff. XXVv-XXVIIr, XXXv-XXXIv. 
y perderse buena parte de los barcos, naufragando, varando o simplemente desapareciendo en el mar, en un área tan vasta como la comprendida entre el estuario del Tajo, frente a Lisboa, y la isla de Tarifa ${ }^{29}$. Probablemente se trate de la descripción más detallada conocida para ese momento y otros anteriores del conjunto de la costa del golfo de Cádiz, entre el cabo de San Vicente y Gibraltar, aún más exhaustiva que la recogida por el licenciado Andrés de Poza para esta región en 1585 , que podría ser el texto con el que mejor pudiera ser comparado ${ }^{30}$. Resulta difícil precisar los motivos que condujeron a su elaboración pero de nuevo hay que pensar en un requerimiento surgido desde el gobierno de la monarquía española, esta vez vinculado acaso con el control del tráfico naval hacia Indias, que se traduciría en una información general sobre los puertos y barras del litoral atlántico del Algarve y de Andalucía. La precisión técnica en sus informaciones lleva a pensar que su autor fuera un buen entendido en la tratadística náutica del siglo XVI y de los conocimientos reglados y prácticos manejados por los pilotos veteranos en la navegación en esta costa, lo que podría apuntar hacia un marino andaluz u otra

29. El tornaviaje de la flota de Cosme Rodríguez Farfán desde América a España terminó convirtiéndose en una tragedia mayúscula a causa de la pérdida de un buen número de barcos, de la carga transportada y de vidas, incluida la San Andrés, nao capitana de Farfán, frente a la playa de Zahara el 22 de enero de 1555. Estos acontecimientos, sin embargo, han dejado una importante huella documental, en buena medida por la investigación que motivó el descubrimiento de que la San Andrés transportaba grandes cantidades de metales preciosos no declarados, fraude en el que actuaron en connivencia el mismo capitán de la flota, el propietario de la nao y algunos importantes magistrados de la Audiencia del Nuevo Reino de Granada. Sobre el viaje y naufragios de la flota, vid. AGS, Cámara de Castilla. Diversos, Ca $.40, n^{\circ} 67$ (6); AGI, Contratación, leg. 2.000 y 5.108; AGI, Consulado, leg. 841, nº. 5; Catálogo de la Colección de don Juan Bautista Muñoz. Documentos interesantes para la Historia de América. Tomo II, Madrid, Real Academia de la Historia, 1955, pp. 278, 289, 297, 304-306, 309-310, 315 , 317-318, 481-482; E. LORENZO SANZ. Comercio de España con América en la época de Felipe II, 2 Vols., Valladolid, Diputación Provincial de Valladolid, 1979, Vol. II, p. 390; A. FLORES MOSCOSO. "Naufragios en el golfo de Cádiz", en B. TORRES RAMÍREZ, J.J. HERNÁNDEZ PALOMO. (ed.) Andalucía y América en el siglo XVI. Actas de las II Jornadas de Andalucía y América, [celebradas en la] (Universidad de Santa María de la Rábida, marzo, 1982), Consejo Superior de Investigaciones Científicas (CSIC)-Escuela de Estudios Hispano-Americanos, Sevilla, 1983, Vol. I, pp. 333-360, en concreto pp. 349-352; P.E. PÉREZ MALLAÍNA BUENO. El hombre frente al mar. Naufragios en la Carrera de Indias durante los siglos XVI y XVII, Sevilla, Universidad de Sevilla, 1996, pp.43, 89, 91.

A la hora de determinar una posible datación del documento, a resultas de la consulta de la bibliografía citada, el autor de la relación no refleja ninguna referencia a otros naufragios posteriores sufridos en el golfo de Cádiz o al remontar el Guadalquivir hacia Sevilla por las naves de la carrera de Indias, que se conocen por ejemplo para 1561, 1563 y 1592. Tampoco se aprecia en el contenido del texto un posible influjo a partir de las descripciones hidrográficas de las costas atlánticas hispanas que aparecen en el tratado de Andrés de Poza impreso en 1585 (A. DE POÇA. Hydrografia la mas curiosa que hasta aqui ha salido a luz : en que de mas de vn derrotero general, se enseña la nauegacion por altura y derrota, y la del Este Oeste: conla Graduacion de los puertos, y la nauegacion al Catayo por cinco vias diferentes, compuesto por el Licenciado Andres de Poça, Bilbao, Matías Mares, 1585, Libro Segundo, Capítulos I-VI, ff. 2v-21r.). Aunque paleográficamente el tipo de letra manejado puede plantear alguna duda, referencias en estimaciones de distancia con expresiones como "... va de luengo de la costa de las Harenas Gordas obra de vn tiro de arcabuz...” (f. 3r) o “... que es limpio y estarán vn tiro de lombarda de tierra." [f. 1r (vid. nota 50)], en combinación con los otros argumentos que aportó,. invitan a considerar que la descripción original estuviera fechada en el tercer cuarto del siglo XVI, aunque posiblemente el documento pudiera ser una copia bastante posterior de la misma.

30. AGI, Indiferente General, $C^{\mathrm{a}} .1 .528, \mathrm{n}^{\circ} 44$. 
persona con conocimientos navales y cosmográficos reconocidos, ligada de algún modo al entorno de la Casa de la Contratación de Sevilla ${ }^{31}$.

La relación expuesta por el autor se corresponde con fidelidad a la descripción que hace de la misma en su inicio, por más que aquélla se extienda más al sur del cabo de Trafalgar hasta alcanzar Gibraltar. En efecto, nos encontramos ante una memoria notablemente precisa de los accidentes geográficos de esta costa y de sus puertos y fondeaderos señeros, aportando toda suerte de detalles sobre las referencias a considerar para su práctica. Así, notifica las distancias entre puntos en leguas, las calidades de puertos, los regímenes de corrientes y vientos a tener en cuenta para la navegación de cabotaje y la entrada y salida en los surgideros, además de los potenciales peligros que se encontraban en el litoral por la presencia, fundamentalmente, de bajas en zonas habitualmente transitadas por los navíos que surcaban el litoral del golfo de Cádiz. Además de la consideración de los que apunta como barras y surgideros adecuados para fondear según el calado de las naves desde Ayamonte a Gibraltar -las barras de Ayamonte, Huelva y Sanlúcar, la bahía de Cádiz y, dentro de ella, la del Puntal, la cala de San Clemente en altamar frente a Sancti Petri, la playa de Conil, la barra de Barbate, la costa de Zahara de los Atunes y toda la bahía de Algeciras- son de sumo interés las múltiples señales que aporta tanto para el reconocimiento desde el mar de los lugares de la costa para mejor orientación del navegante como las descripciones de los fondos y bajas de mayor peligro, ligadas a las referencias de sondeo de profundidad en brazas, composición de tales fondos y distancia de los mismos respecto al litoral. Buenos ejemplos de ello son los consejos para salvar los escollos que se encuentran en el acceso a la barra de Sanlúcar o a la bahía de Cádiz o los bajíos de cabo Trafalgar y de la punta del Carnero y Tarifa para acceder a la bahía de Algeciras ${ }^{32}$.

Sin duda, este conjunto de fuentes plantea el problema de su datación tardía a lo largo del siglo XVI. Es evidente, entonces, el riesgo de extrapolar las informaciones en ellas vertidas a épocas anteriores, tanto por lo que respecta a la importancia de determinados puertos y fondeaderos como por lo que toca al nivel de detalle y sistematización que, en los siglos XIV y XV, pudieran manejar usualmente los marineros que operaban en la costa andaluza sobre distancias entre puntos de la costa y sondeo de los fondos marinos. Aun así, la recopilación y puesta por escrito de estas informaciones nos coloca sobre la pista de un sustrato medieval de conocimiento náutico acerca de la navegación de cabotaje en la Andalucía atlántica que merece ser rastreado y que podía ser ya bastante preciso en cuanto a recono-

31. Puede resultar ilustrativo de ello el encabezamiento que hace del documento el autor: "Relación de los puertos y barras que ay en la costa dende el cabo de Sant Vicente hasta el cabo de Trafalgar y las señales de tierra que sobre los dichos puertos ay y el fondo y señales de sonda que assimismo tiene cada puerto y remitiéndome a algún mejor rotero que en ello puede auer en alguna parte d'ella" (Ibidem, f. 1r).

32. Ibidem, ff. 3r-4v, 5v. La comparación con las referencias ofrecidas en la Hydrografia de Andrés de Poza resultan pertinentes, al observarse divergencias notables. Buen ejemplo lo representan las citas a puertos y accidentes geográficos significativos en ella, que remiten a Ayamonte, San Miguel sobre la barra de Lepe, Lepe, Saltés, Palos, Sanlúcar, Chipiona, Cádiz, cabo Trafalgar, punta de Tarifa y Gibraltar (A. DE POÇA. Hydrografia ..., Libro Segundo, Capítulos I-VI, ff. 2v-3v, 8v-10r). 
cimiento de los vientos activos, estimación de distancia entre puntos de la costa, situación de bancos de arena y rocosos a tener en cuenta en ella, conocimiento de los acceso a los puertos marítimos a y fluviales, etc. Datos, en fin, muy a tener en cuenta por lo que respecta, al menos, a dos cuestiones. Por una parte, la comprensión de los ciclos y escalas de la navegación a larga distancia en esta zona en la Baja Edad Media y, por la otra, el recurso a marinos locales o veteranos en estas costas por mercaderes y patrones extranjeros para asegurar el acceso a los puertos de sus navíos ${ }^{33}$.

\section{4.- ViAJES POR MAR Y ACCIONES NAVALES EN LA ANDALUCÍA ATLÁNTICA EN LAS FUENTES LITERARIAS}

Quiero concluir estas páginas llamando la atención sobre el interés de retornar a las fuentes de carácter literario como un recurso fundamental para conocimiento del espacio geográfico de la Andalucía atlántica y de las prácticas navales desarrolladas en este su ámbito marítimo durante la Baja Edad Media. Su estructura narrativa, basada en experiencias personales de primera o segunda mano o en el acceso a documentación original contemporánea, hacen de estos relatos una fuente de alto valor, cuando menos, cualitativo, al transmitirnos gran número de detalles realistas sobre las cuestiones que estamos abordando, como pueden ser las descripciones de puertos y ciudades, el ejercicio de singladuras concretas y los pormenores de estos viajes. Atender a estas noticias sin duda puede ayudar a los investigadores a complementar los datos, a menudo mucho más parcos aunque, acaso, cuantitativamente más representativos, extraídos del análisis sistemáticos de la documentación notarial, contable o cartográfica, dotándonos todo ello de una imagen mucho más equilibrada sobre el desarrollo marítimo de la baja Andalucía en los siglos finales del Medievo. Aunque la exhaustividad a la hora de hacer una valoración de estos textos resulta aquí imposible, al menos querría presentar algunos ejemplos ilustrativos, bien por lo conocido de estos relatos, bien por haber sido objeto ya de análisis en este sentido, bien por su potencialidad de cara a futuras investigaciones.

33. González Arévalo señala algunos de estos aspectos y el reclutamiento de marinos castellanos por las galeras florentinas de Poniente (R. GONZÁLEZ ARÉVALO. "La costa del reino de Sevilla...", pp. 315-316), además de la contrata, directamente, de naves castellanas, muchas de ellas vizcaínas, por mercaderes de Florencia para el transporte hasta Italia de productos hispanos, citando a Jacques Heers (J. HEERS, "Le commerce des Basques en Méditerranée au XVe. siècle (d'après les archives de Gênes)", Bulletin Hispanique, 57, 1955, pp. 292-324, en concreto pp. 309, 316); R. GONZÁLEZ ARÉVALO. "Corso, comercio y navegación en el siglo XV: Castilla y las galeras mercantiles de Florencia", En la España medieval, 34, 2011, pp. 61-95, en particular p. 90). Testimonios en este mismo sentido acerca de la contrata de marinos andaluces y castellanos por parte de navegantes florentinos y venecianos en el siglo XV para el gobierno de sus barcos en la navegación por las costas atlánticas han sido puestos de manifiesto recientemente por M. BOCHACA en su conferencia "Del Mediterráneo al Atlántico: parla y representaciones marineras en la primera mitad del siglo XV", de pronta publicación (Cuadernos del Cemyr, 22, 2014). 
La navegación por el estrecho de Gibraltar entre el Mediterráneo y el Atlántico seguida por navíos comerciales genoveses ocupa un lugar a reconocer en algunos de los más famosos escritos castellanos del siglo XV que habitualmente han sido considerados bajo el epíteto de "relatos de viaje" ${ }^{34}$, como son la Embajada a Tamorlán, de Ruy González de Clavijo, entre 1403 y 1406, y las Andanzas y viajes de Pedro Tafur, entre 1436 y $1439^{35}$. En el primero se nos describe su partida desde El Puerto de Santa María para desplazarse en barca hasta Cádiz, donde embarcó la embajada en una carraca genovesa en el puerto de las Muelas de esta ciudad, que en el término de dos días cruzó el estrecho de Gibraltar hasta alcanzar en un tercero el puerto de Málaga, donde tras una escala de cinco días, la nave bordeó la costa mediterránea sin tocar puerto durante dos días para tomar rumbo hacia las islas Baleares. Del mismo modo, se relata el retorno hacia Castilla desde Génova, en un viaje de un mes de duración, hasta llegar el 1 de marzo de 1406 a Sanlúcar de Barrameda, desde donde el embajador continuaría su viaje por tierra para presentar sus informes al rey Enrique III $^{36}$. A su vez, Pedro Tafur, tras narrar su participación en el sitio de Gibraltar después de embarcar en una nao gallega en Sanlúcar de Barrameda y retornar posteriormente a este puerto, detalla su embarque en una carraca genovesa con la que iniciaría su viaje hacia el Mediterráneo en dirección a Génova. El viaje hasta Gibraltar aporta interesantes detalles acerca de la navegación de cabotaje hasta el estrecho y el retorno hacia la bahía de Cádiz -más próximo a la costa en la ida que en la vuelta aunque sin perderla de vista- y sobre las características de la bahía de Algeciras y de la plaza sitiada. A su vez, el periplo en la embarcación genovesa nos pone al corriente de datos valiosos sobre el tráfico comercial en el estrecho de Gibraltar desarrollado por los mercaderes y marinos de esta república italiana y el peligro inherente que suponía el posible ataque de naves hostiles, con las descripciones de las costas y puertos correspondientemente recorridos. Cita, de este modo, la importancia de las escalas comerciales en Cádiz, Arzila, en la costa atlántica de Berbería, y Málaga, ya en el reino de Granada, dentro de las rutas de larga distancia seguidas por los genoveses, que conectaban el Mediterráneo con el Atlántico hasta Flandes. Igualmente, narra las vicisitudes

34. Sobre este género, a modo introductorio, vid. R. BELTRÁN LLAVADOR. "Los libros de viajes medievales castellanos. Introducción al panorama crítico actual: ¿cuántos libros de viajes medievales castellanos?", Revista de Filología Románica, Extra 1 (Ejemplar dedicado a Los libros de viajes en el mundo románico), 1991, pp. 121-164; R. BELTRÁN LLAVADOR. (ed.) Maravillas, peregrinaciones y utopías. Literatura de viajes en el mundo románico, Valencia, Universitat de València, 2002; E. AZNAR VALLEJO. "Introducción a los viajes medievales. Una mirada geográfica y cultural", en J.I. DE LA IGLESIA DUARTE. (ed.) Viajar en la Edad Media. XIX Semana de Estudios Medievales, Nájera, 2008, Logroño, Instituto de Estudios Riojanos, 2009, pp. 19-48.

35. R. GONZÁLEZ DE CLAVIJO (F. LÓPEZ ESTRADA. ed., introducc. y notas), Embajada a Tamorlán, Madrid, Castalia, 1999; P. TAFUR, (M. JIMÉNEZ DE LA ESPADA, ed.) Andanças e viajes de Pero Tafur. Por diversas partes del mundo avidos 1435-1439, Madrid, Imprenta de Miguel Ginesta, 1874 (ed. facsímil, Barcelona, El Albir, 1982).

36. R. GONZÁLEZ DE CLAVIJO (F. LÓPEZ ESTRADA. ed., introducc. y notas), Embajada a Tamorlán, pp. 80-83, 355-359. Dentro de la extensa bibliografía acerca de este relato, una primera aproximación en F. LÓPEZ ESTRADA. "Ruy González de Clavijo. La embajada a Tamorlán. Relato del viaje hasta Samarcanda y regreso (1403-1406)”, Arbor, CLXXX, 711/712, 2005, pp. 515-535. 
de la navegación en conserva junto a otras carracas genovesas y naos castellanas para reducir el riesgo que se preveía de ataques aragoneses, dando lugar a escalas técnicas para reunir las naves y tomar informaciones sobre los potenciales enemigos en Ceuta y posteriormente en Cartagena para poner finalmente rumbo hacia las Baleares en pos de Génova ${ }^{37}$.

Otro relato de particular valor para el conocimiento de estas navegaciones en las costas andaluzas entre el Atlántico y el Mediterráneo, en esta ocasión protagonizado por galeras armadas, es el ofrecido por El Victorial, biografía caballeresca de Pero Niño en la que se describen las acciones navales al servicio del rey Enrique III en 1404 en aguas del Mediterráneo contra el corso berberisco y en 1405-1406 en el golfo de Vizcaya y el canal de la Mancha en apoyo de los franceses en guerra contra Enrique V de Inglaterra ${ }^{38}$. Si las campañas corsarias frente a los ingleses en las costas de Gascuña y de las islas Británicas escapan de nuestros intereses aquí, al organizarse desde el puerto de Santander y con navíos cantábricos, las acciones mediterráneas, aunque se realizaron con base en Cartagena, fueron preparadas desde las atarazanas de Sevilla, con el armamento de dos galeras y una nao, dando lugar a la narración de estos preparativos y de la singladura desde la partida desde Sevilla en mayo de 1404 hasta alcanzar Cartagena ${ }^{39}$, relatándose posteriormente aunque de un modo más breve el retorno a la ciudad hispalense en diciembre de ese año ${ }^{40}$. El texto confeccionado por Gutierre Díez de Games, extremadamente detallado en lo todo lo que se refiere a los pormenores de la navegación y las condiciones del mar durante la misma, de las acciones de abordaje y cabalgada y de las descripciones de costas y lugares poblados, ha sido objeto de análisis de gran agudeza por lo que se refiere a todo su perfil naval, poniendo de manifiesto su valor extraordinario como fuente. Éstos han puesto de manifiesto la dependencia del mismo de documentos previos que hubieron de servir como fuente directa para su composición. Fundamentalmente, los “diarios” levantados por los escribanos que habían de servir en las galeras reales, memoriales presentados por Pero Niño ante la Corte para rendir cuenta de su servicio, otros documentos manejados por la cancillería regia relativos al conjunto de estas acciones militares e incluso otros relatos cronísticos como la misma Crónica de Juan II de Álvar García de Santa

37. R. GONZÁLEZ DE CLAVIJO (F. LÓPEZ ESTRADA, ed., introducc. y notas). Andanças e viajes..., pp. 3-10.

38. G. DÍAZ DE GAMES (R. BELTRÁN LLAVADOR, ed.). El Victorial, Salamanca, Ediciones Universidad de Salamanca, 1997, caps. 37-50, pp. 375-433. Una descripción de estos episodios bélicos navales en C. MARTÍNEZ VALVERDE. "Un capitán español del siglo XV. El caballero castellano Don Pero Niño, Conde de Buelna”, Revista de Historia Militar, 57, 1984, pp. 9-53, en concreto pp. 19-39; IDEM. "La nota marinera en La Crónica de Don Pero Niño", Revista de Historia Naval, 8, 1985 , pp. 15-44.

39. G. DÍAZ DE GAMES (R. BELTRÁN LLAVADOR, ed.). El Victorial, cap. 37, pp. 375-383.

40. Ibidem, pp. 430-433. Contamos con un estudio muy completo de la campaña mediterránea de Pero Niño y su contextualización dentro del ambiente de relaciones entre la Corona de Castilla y la Corona de Aragón alrededor de la lucha contra la piratería y la salvaguarda de los intereses de ambas monarquías y de sus respectivos súbditos en el Mediterráneo Occidental en M ${ }^{\mathrm{a}}$.T. FERRER I MALLOL. "Els corsaris castellans i la campanya de Pero Niño al Mediterrani (1404). Documents sobre «El Victorial»”, AEM, 5, 1968, pp. 265-338. 
María. Así lo han puesto de manifiesto los estudios de $\mathrm{M}^{\mathrm{a}}$. Teresa Ferrer i Mallol y Rafael Beltrán Llavador ${ }^{41}$. A su vez, los estudios de Eduardo Aznar Vallejo y Michel Bochaca, de próxima aparición impresa, subrayan las características del desempeño náutico de las galeras de combate mediterráneas, sus necesidades, virtudes y dificultades en distintas situaciones de estado de la mar y de disponibilidad de refugio y abastecimiento, comparando las experiencias de estos tipos de barcos de fondo plano en el Mediterráneo y en el Atlántico en la Baja Edad Media frente a la del desarrollo de navíos de quilla redonda como las carracas, naos y carabelas ${ }^{42}$.

Apenas se trata de unos ejemplos bien conocidos y que pueden colocarnos en situación de tomar en consideración la potencialidad de estas fuentes narrativas. No obstante, es posible ampliar este elenco de textos y, a razón de ello, las propuestas de aproximación metodológica al estudio de costas, puertos y navegación en la Andalucía atlántica. Abundando en las narraciones de viaje, algunos de los más conocidos desde el siglo XIX describen parte de su desarrollo por esta zona o algunas de las principales ciudades andaluzas. Es el caso del caballero germanopolaco Nicolaus von Popplau, quien en su itinerario por Castilla, Portugal y Aragón en 1484-1485, tras visitar la tumba del apóstol Santiago y la corte portuguesa en Lisboa, continuaría su periplo por vía naval desde la capital lusa hacia los puertos del Algarve hasta arribar a Lepe y, en último término, después de pasar por Gibraleón y Niebla por tierra, alcanzar Cádiz, Sanlúcar y al fin arribar a Sevilla de nuevo navegando ${ }^{43}$. Conocidas son también las descripciones de los puertos de Almería, Málaga y Sevilla de la mano de Hieronymus Münzer en su recorrido por los territorios de la monarquía de los Reyes Católicos y por Portugal entre 1494 y $1495^{44}$. Puede extenderse este listado a otros nombres de viajeros que visitaron los reinos ibéricos con anterioridad a finales del siglo $\mathrm{XVI}^{45}$, no habiendo de olvidarse

41. Ma.T. FERRER I MALLOL. "Els corsaris castellans...”, pp. 309-313; R. BELTRÁN LLAVADOR. "Del «diario de a bordo» a la biografía: las campañas marítimas (1407 y 1410) en la Crónica de Juan II de Álvar García de Santa María y la doble redacción de El Victorial", AEM, 20, 1990, pp. 171-209.

42. M. BOCHACA ha abordado las campañas navales de Pero Niño en su conferencia ya citada “Del Mediterráneo al Atlántico...”. Más específicamente, estas cuestiones son tratadas en el artículo de M. BOCHACA, E. AZNAR VALLEJO. "Navigation atlantique de trois galères castillaines au debut du XVe siècle d'après Le Victorial: de la chronique chevaleresque à l'histoire maritime", $A E M, 43 / 2$, 2013 (en prensa).

43. J. LISKE. (comp.) Viajes de extranjeros por España y Portugal en los siglos XV, XVI y XVII, Madrid, Medina, 1878, pp. 15-65, en concreto pp. 40-42.

44. L. PFANDL. (ed.) "Itinerarium Hispanicum Hieronymi Monetarii. 1494-1495", Revue Hispanique, 113, 1920, pp. 1-179, en concreto pp. 34-40, 68-82. Véase, para su edición traducida al castellano, J. PUYOL. (traducc. y ed.) "Jerónimo Münzer. Viaje por España y Portugal en los años 1494 y 1495", Boletín de la Real Academia de la Historia, 84, 1924, pp. 32-119, 197-279, en concreto pp. 7782, 113-119, 197-204; o J. MÜNZER. (M. GÓMEZ MORENO. prólogo, J. LÓPEZ TORO, traducc.) Viaje por España y Portugal. 1494-1495, Madrid, Colección Almenara. Talleres Aldus S. A., 1951.

45. Buen ejemplo de ello se puede encontrar en J. GARCÍA MERCADAL. (ed.) Viajes de extranjeros por España y Portugal. Desde los tiempos más remotos hasta comienzos del siglo XX. Vol. I (6 Vols.), Valladolid, Junta de Castilla y León. Consejería de Educación y Cultura, 1999. Una listado bien documentado de estos viajes y de las referencias bibliográficas de sus ediciones en la web Exploradores y viajeros por España y el nuevo mundo (http://www.cervantesvirtual.com/bib/portal/exploradores/pcuartonivele721.html?conten=viajeros; consultado el 14-IV-2013). 
tampoco otros relatos de gran interés. Es el caso de los deparados por navegantes italianos en expediciones mercantiles hacia el Atlántico, como el diario del florentino Luca di Maso degli Albizzi como capitán de las galeras de Poniente de Florencia - cuya ruta conectaba el comercio florentino desde Porto Pisano hasta los puertos del Mar del Norte, circunnavegando para ello la Península Ibérica- en 1429-143046, o la extraordinaria relación de Pietro Querini del infortunado viaje iniciado en la isla de Creta por la carraca veneciana Querina hasta su naufragio al norte de las islas Británicas, el posterior rescate de una mínima parte de su tripulación superviviente en las islas Lofoten al norte de Noruega y su retorno a Venecia a lo largo de los años 1431 y $1432^{47}$. O, en un contexto totalmente distinto, del que recoge la navegación entre Portugal y el Mediterráneo a través del estrecho de Gibraltar como el relativo al viaje de la infanta Leonor de Portugal desde Lisboa a Porto Pisano, entre octubre de 1451 y enero de 1452 para la celebración de su matrimonio con el emperador Federico III $^{48}$.

De un modo similar, los relatos cronísticos hispanos vienen a convertirse en una fuente de primer orden para este mismo fin. Rafael Beltrán evidenció el recurso a testimonios documentales manejados por la cancillería castellana en la redacción de los pasajes de la Crónica de Juan II de Álvar García de Santa María referidos a las acciones militares en el estrecho de Gibraltar capitaneadas por el almirante Alfonso Enríquez durante las campañas de 1407 y 1410 de la guerra contra Granada ${ }^{49}$. Ello nos lleva considerar el conjunto de la cronística real castellana desde mediados del siglo XIII hasta el reinado de los Reyes Católicos, donde los episodios navales que van desde la conquista de Sevilla por Fernando III hasta los combates y cabalgadas contra los portugueses, granadinos y norteafricanos durante el reinado de Isabel y Fernando ocupan un buen número de páginas de gran valor para el reconocimiento del espacio costero y la red portuaria de la baja Andalucía en los últimos siglos de la Edad Media ${ }^{50}$. Pero, a la par, tampoco ha de dejarse de

46. Fue editado en M. E. MALLET. The Florentine galleys in the Fifteenth Century, Oxford, Clarendon Press, 1967. Para el paso por las costas andaluzas en su derrota hacia el canal de la Mancha, pp. 222-224. En cuanto a la actividad comercial de las galeras florentinas de Poniente en relación con Castilla, vid. R. GONZÁLEZ ARÉVALO. “Corso, comercio y navegación...", en particular pp. 65-75 por lo que se refiere a la ruta seguida por aguas ibéricas, en la que destacaba especialmente la escala en Cádiz.

47. P. QUERINI, N. DE MICHIELE, C. FIORAVANTE. (P. NELLI, ed.) Il naufragio della Querina. Veneziani nel circolo polare artico, Roma, Nutrimenti, 2007. De nuevo, M. BOCHACA ha analizado de manera comparativa tanto los relatos de Luca di Maso como el de Pietro Querini y sus compañeros y el de Díaz de Games en El Victorial en el trabajo ya aludido "Del Mediterráneo al Atlántico".

48. M. LANCKMANN DE VALCKENSTEIN, "Historia Disponsationis Frederici III cum Eleanora Lusitanica", en A. CAETANO DE SOUSA. Provas da Historia Genealogica da Casa Real Portugueza, Tomo I, Lisboa, Officina Sylviana da Academia Real, 1739, Num. 53, An. 1503, pp. 601-633.

49. R. BELTRÁN LLAVADOR. "Del «diario de a bordo»...”, pp. 185-192; A. GARCÍA DE SANTA MARÍA. (J. DE M. CARRIAZO, ed.) Crónica de Juan II de Castilla, Madrid, Real Academia de la Historia, 1982, caps. 37-38, pp. 109-116, cap. 173, pp. 367-375, cap. 193, pp. 408-409.

50. Un modesto ejemplo del manejo de las crónicas del siglo XIV y del Libro de la Montería de Alfonso XI para la zona del estrecho de Gibraltar en torno a Tarifa en G.J. CUESTA ESTÉVEZ. "Sobre toponimia de la costa norte del Estrecho de Gibraltar en el siglo XIV", Almoraima. Revista de estudios campogibraltareños, 29, 2003, pp. 289-297. 
lado el testimonio de las crónicas portuguesas de Fernão Lopes, Gomes Eanes de Zurara, Rui de Pina y Damião de Góis, que cubren el arco temporal desde mediados del siglo XIV hasta principios del siglo XVI y dan cuenta de un buen número de acciones navales en el golfo de Cádiz y el estrecho de Gibraltar en el contexto de las relaciones luso-castellanas en este período, a menudo hostiles, y de la expansión portuguesa hacia África inaugurada con la conquista de Ceuta en $1415^{51}$.

\section{5.- RECAPITULACIÓN}

El recorrido que acabo de realizar por las fuentes literarias de interés para el estudio del espacio físico costero de la Andalucía atlántica al final de la Edad Media y de la navegación practicada en él en esa época, más allá de la acumulación de un buen número de referencias altamente representativas para su interpretación analítica, está lejos de ser exhaustivo. Sin duda, este elenco de testimonios narrativos está sujeto a su futura ampliación, abierta a otros relatos cronísticos regios o particulares y memorias de viajes occidentales - por no citar los producidos por autores islámicos ${ }^{52}-$, y a la sistematización de una metodología de trabajo que pueda facilitar un tratamiento unificado de las informaciones extraídas de lo que puede vislumbrarse como un corpus ciertamente heterogéneo. En cualquier caso, la abundancia de este tipo de noticias de carácter narrativo, en muchos casos fruto de la observación directa o del acceso a documentación original hoy perdida, a lo largo de un amplio arco cronológico ha de ser considerada muy positivamente. Así, su notable valor cualitativo obliga a considerarlas en combinación con las informaciones aportadas por las fuentes escritas y cartográficas y por las evidencias arqueológicas para una mejor interpretación de transformaciones en la geografía humana de la costa andaluza y en las dinámicas políticas, sociales y económicas a las que se liga la navegación por ella durante la Baja Edad Media.

A su vez, creo que es posible afirmar que, también a partir de lo expuesto acerca de la cartografía y la documentación náutica de tipo técnico-descriptivo de la época, los conjuntos de fuentes en los que me he concentrado a lo largo de estas líneas merecen ser fruto de reflexión como bases para futuros trabajos. La aparición en los últimos años de un buen ramillete de monografías y artículos que se apoyan en las noticias contenidas en estos testimonios narrativos y documentales, escritos y gráficos, evidencian su potencialidad para abrir nuevas vías en la investigación acerca de la Historia marítima de la Castilla medieval. Pero su análisis

51. Una reciente muestra de su aplicación, de nuevo para el estrecho de Gibraltar y el eje Tarifabahía de Algeciras-Ceuta-Tánger-Arzila en J.L. GÓMEZ BARCELÓ. "Tarifa en las crónicas lusas referidas a la costa africana del Estrecho", Al Qantir. Monografias y documentos sobre la Historia de Tarifa, 11, 2011, pp. 133-163.

52. Un buen ejemplo a este respecto puede hallarse en la influencia de las aportaciones geográficas insertas la obra de Ibn Jaldūn de la segunda mitad del siglo XIV, directamente subsidiarios de los de al-Idrīsī, fechados en el siglo XII, en otros autores islámicos. Vid. F. FRANCO SÁNCHEZ, "Geografía y cartografía en la obra de Ibn Jaldūn”, en J.L. GARROT GARROT, J. MARTOS QUESADA. (ed.) Miradas españolas sobre Ibn Jaldún, Madrid, Ibersaf, 2008, pp. 195-217. 
intensivo, sin duda, tiene aún mucho que decirnos. De un modo muy directo, sobre la percepción de este espacio marítimo de la baja Andalucía durante el final de la Edad Media y los albores de la Edad Moderna. Esto es, sobre la transformación de tales imágenes acerca del mismo a lo largo del tiempo y sobre la convivencia de percepciones diferenciales de ese espacio, expresadas en la materialidad del documento escrito, la carta de navegación, el tratado náutico o el relato literario, entre los distintos agentes sociales e instancias de poder que interactuaban en él, lo concebían y construían (la monarquía y sus servidores, las poblaciones locales ligadas al mundo del mar, mercaderes y visitantes extranjeros, estudiosos y científicos, etc.). Y, en definitiva -y dando un paso más allá- sobre la evolución del territorio atlántico andaluz durante ese tránsito entre los siglos XIV y XVI. O lo que es lo mismo, la de su entidad demográfica, política, social y económica, en relación con la propia evolución de su red portuaria en este período de intensificación de los contactos entre ámbitos mediterráneo y atlántico y de expansión de la sociedad del Occidente cristiano medieval, precisamente de cara al Atlántico. Efectivamente, tal y como fue percibida, comprendida y transmitida por los seres humanos que participaron en este proceso histórico.

\section{BibLIOGRAFÍA}

Fuentes publicadas

ARROYAL ESPIGARES, P., CRUCES BLANCO, E. y MARTÍN PALMA, Ma.T. Cedulario del reino de Granada (1511-1514), Málaga, Universidad de Málaga, 2008.

GARCÍA MERCADAL, J. (ed.) Viajes de extranjeros por España y Portugal. Desde los tiempos más remotos hasta comienzos del siglo XX. Vol. I (6 Vols.), Valladolid, Junta de Castilla y León. Consejería de Educación y Cultura, 1999.

GARCÍA DE SANTA MARÍA, Á. (CARRIAZO, J. de M. ed.) Crónica de Juan II de Castilla, Madrid, Real Academia de la Historia, 1982.

GONZÁLEZ DE CLAVIJO, R. (LÓPEZ ESTRADA, F. ed., introducc. y notas), Embajada a Tamorlán, Madrid, Castalia, 1999.

LANCKMANN DE VALCKENSTEIN, N. "Historia Disponsationis Frederici III cum Eleanora Lusitanica", en CAETANO DE SOUSA, A. Provas da Historia Genealogica da Casa Real Portugueza, Tomo I, Lisboa, Officina Sylviana da Academia Real, 1739, Num. 53, An. 1503, pp. 601-633.

LISKE, J. (comp.) Viajes de extranjeros por España y Portugal en los siglos XV, XVI y XVII, Madrid, Medina, 1878.

MÜNZER, J. (GÓMEZ MORENO, M. prólogo, LÓPEZ TORO, J. traducc.) Viaje por España y Portugal. 1494-1495, Madrid, Colección Almenara. Talleres Aldus S. A., 1951.

PAGNINI DEL VENTURA, G. Della decima e di varie altre gravezze imposte dal Comune di Firenze. Della moneta e della Mercatura de fiorentini fino al secolo 
XVI, vol. IV: Contenente la Pratica della Mercatura scritta da Giovanni di Antonio da Uzzano (nel 1442), Lisboa-Lucca, 1766 (facsímil de Forni Ed., vol. II, Bolonia, 1967, pp. 199-276).

PFANDL, L. (ed.) "Itinerarium Hispanicum Hieronymi Monetarii. 1494-1495", Revue Hispanique, 113, 1920, pp. 1-179.

POÇA, A. DE. Hydrografia la mas curiosa que hasta aqui ha salido a luz : en que de mas de vn derrotero general, se enseña la nauegacion por altura y derrota, y la del Este Oeste: conla Graduacion de los puertos, y la nauegacion al Catayo por cinco vias diferentes, compuesto por el Licenciado Andres de Poça, Bilbao, Matías Mares, 1585.

PUYOL, J. (traducc. y ed.) “Jerónimo Münzer. Viaje por España y Portugal en los años 1494 y 1495”, Boletín de la Real Academia de la Historia, 84, 1924, pp. 32-119, 197-279.

QUERINI, P., MICHIELE, N. DE. y FIORAVANTE, C. (NELLI, P. ed.) Il naufragio della Querina. Veneziani nel circolo polare artico, Roma, Nutrimenti, 2007.

TAFUR, P. (JIMÉNEZ DE LA ESPADA, M. ed.) Andanças e viajes de Pero Tafur. Por diversas partes del mundo avidos 1435-1439, Madrid, Imprenta de Miguel Ginesta, 1874 (ed. facsímil, Barcelona, El Albir, 1982).

Monografías, artículos en revistas científicas, capítulos de libros y contribuciones a congresos

Spazi, tempi, misure e percorsi nell'Europa del Bassomedioevo. Atti del XXXII Convegno storico internazionale. Todi, 8-11 ottobre 1995, Spoleto, 1996.

AZNAR VALLEJO, E. "Cádiz y su región en la expansión atlántica", Estudios de Historia y Arqueología medievales, 10, 1994, pp. 11-23.

—. "Del mar soñado al mar hollado. El redescubrimiento del Océano", Cuadernos del Cemyr, 15, 2007, pp. 175-195.

—. "Introducción a los viajes medievales. Una mirada geográfica y cultural", en IGLESIA DUARTE, J.I. DE LA (ed.) Viajar en la Edad Media. XIX Semana de Estudios Medievales, Nájera, 2008, Logroño, Instituto de Estudios Riojanos, 2009, pp. 19-48.

BELTRÁN LLAVADOR, R. "Del «diario de a bordo» a la biografía: las campañas marítimas (1407 y 1410) en la Crónica de Juan II de Álvar García de Santa María y la doble redacción de El Victorial", Anuario de Estudios Medievales, 20, 1990, pp. 171-209.

—. "Los libros de viajes medievales castellanos. Introducción al panorama crítico actual: ¿cuántos libros de viajes medievales castellanos”, Revista de Filología Románica, Extra 1, 1991 (Ejemplar dedicado a: Los libros de viajes en el mundo románico), pp. 121-164.

BELTRÁN LLAVADOR, R. (ed.) Maravillas, peregrinaciones y utopias. Literatura de viajes en el mundo románico, Valencia, Universitat de València, 2002. 
BELLO LEÓN, J.M. y MARTÍN PERERA, A. Las atarazanas de Sevilla a fines de la Edad Media, Murcia, Editum. Ediciones de la Universidad de Murcia, 2012.

BELLO LEÓN, J.M., GÓMEZ, V. y GONZÁLEZ ZALACAIN, R.J. "Nuevas propuestas con viejas fuentes: la documentación para el estudio de los puertos andaluces en la Época de los Descubrimientos", en $X X$ Coloquio de Historia Canario-Americana, Cabildo de Gran Canaria-Casa de Colón, Las Palmas de Gran Canaria (en prensa).

BERNAL RODRÍGUEZ, A.M. y COLLANTES DE TERÁN SÁNCHEZ, A. "El puerto de Sevilla, de puerto fluvial medieval a centro portuario mundial (siglos XIV-XVII)", en CAVACCIOCHI, S. (ed.) I porti come impresa economica. Atti della XIX Settimana di Studio, Florencia, Le Monnier, 1988, pp. 779-824.

BIADENE, S. (ed.) Carte da navigar. Portolani e carte nautiche del Museo Correr 1318-1732, Venecia, Mursilio, 1990.

BOCHACA, M. "Del Mediterráneo al Atlántico: parla y representaciones marineras en la primera mitad del siglo XV", Cuadernos del Cemyr, 22, 2014 (en prensa).

BOCHACA, M. y AZNAR VALLEJO, E. "Navigation atlantique de trois galères castillaines au debut du XV siècle d'après Le Victorial: de la chronique chevaleresque à l'histoire maritime", Anuario de Estudios Medievales, 43/2, 2013 (en prensa).

CAMPBELL, T. "19. Portolan Charts from the Late Thirteenth Century to 1500", en HARLEY, J.B. y WOODWARD D. (eds.) The history of cartography. I. Cartography in prehistoric, ancient and medieval Europe and Mediterranean, Chicago-Londres, University of Chicago Press, 1987, pp. 371-463.

CERTEAU, M. DE. La invención de lo cotidiano. 1. Artes de hacer, México, Universidad Iberoamericana, 1996 ( $1^{\mathrm{a}}$ ed. francés, París, 1980).

COLLANTES DE TERÁN SÁNCHEZ, A. "Papel del Atlántico en la configuración de Andalucía", Historia. Instituciones. Documentos, 35, 2008, pp. 85-105.

CUESTA ESTÉVEZ, G.J. "Sobre toponimia de la costa norte del Estrecho de Gibraltar en el siglo XIV", Almoraima. Revista de estudios campogibraltareños, 29, 2003, pp. 289-297.

DÍAZ DE DURANA ORTIZ DE URBINA, J.R. y MUNITA LOINAZ, J.A. (ed.) La apertura de Europa al mundo atlántico. Espacios de poder, economía marítima y circulación cultural, Bilbao, Universidad del País Vasco. Servicio Editorial/Euskal Herriko Unibertsitatea. Argitarapen Zerbitzua, 2011.

FÁBREGAS GARCÍA, A. "Estrategias de los mercaderes toscanos y genoveses en el Reino de Granada a través de la correspondencia Datini”, Serta Antiqua et Mediaevalia. V Società e Istituzioni del Medioevo Ligure, Roma, Giorgio Bretschneider Editore, 2001, pp. 259-304.

—. "Redes de comercio y articulación portuaria del Reino de Granada: puertos y escalas en el tráfico marítimo bajomedieval”, Chronica Nova, 30, 2003-2004, pp. 69-102. 
FERNÁNDEZ DURO, C. Armada española desde la unión de los reinos de Castilla y de León, 9 Vols., Madrid, Estudio tipográfico Sucesores de Rivadeneyra, 1895-1903.

FERRER I MALLOL, Ma.T. "Els corsaris castellans i la campanya de Pero Niño al Mediterrani (1404). Documents sobre «El Victorial»", Anuario de Estudios Medievales, 5, 1968, pp. 265-338.

FLORES MOSCOSO, A. "Naufragios en el golfo de Cádiz", en TORRES RAMÍREZ, B. y HERNÁNDEZ PALOMO, J.J. (ed.) Andalucía y América en el siglo XVI. Actas de las II Jornadas de Andalucía y América, [celebradas en la] (Universidad de Santa María de la Rábida, marzo, 1982), Consejo Superior de Investigaciones Científicas (CSIC)-Escuela de Estudios Hispano-Americanos, Sevilla, 1983, Vol. I, pp. 333-360.

FRANCO SÁNCHEZ, F. “Geografía y cartografía en la obra de Ibn Jaldūn”, en GARROT GARROT, J.L. y MARTOS QUESADA, J. (ed.) Miradas españolas sobre Ibn Jaldún, Madrid, Ibersaf, 2008, pp. 195-217.

GARÍ, B. "La advertencia del fin. Génova y el reino de Granada a mediados del siglo XV", en BOSCOLO, A. y HERNÁNDEZ PALOMO, J.J. (ed.) Presencia italiana en Andalucía. Siglos XIV-XVII. Actas del III Coloquio Hispano-Italiano, Sevilla, Consiglio Nazionale delle Ricerche-Consejo Superior de Investigaciones Científicas (CSIC)-Escuela de Estudios Hispanoamericanos, 1989, p. 179-190.

GARÍ, B. y SALICRÚ I LLUCH, R. "Las ciudades del triángulo: Granada, Málaga y Almería, y el comercio mediterráneo en la Edad Media”, en ABULAFIA, D. y GARÍ, B. (ed.) En las costas del Mediterráneo occidental. Las ciudades de la Península Ibérica y del reino de Mallorca y el comercio mediterráneo en la Edad Media, Barcelona, Omega, 1996, pp. 171-211.

GARCÍA DE CORTÁZAR, J.Á. et al., Organización social del espacio en la España medieval. La Corona de Castilla en los siglos VII a XV, Barcelona, Ariel, 1985.

—. “Organización social del espacio: propuestas de reflexión y análisis histórico de sus unidades en la España medieval”, Studia Historica. Historia Medieval, 6, 1988, pp. 195-236.

—. "Organización del espacio, organización del poder entre el Cantábrico y el Duero en los siglos VIII a XIII”, en GARCÍA DE CORTÁZAR Y RUIZ DE AGUIRRE, J.Á. (ed.) Del Cantábrico al Duero. Trece estudios sobre organización social del espacio en los siglos VIII a XIII, Santander, Universidad de Cantabria, 1999, pp. 15-48.

- Sociedad y organización del espacio en la España medieval, Granada-Valencia, Universidad de Granada-Universitat de València, 2004.

GARCÍA PORRAS, A. y FÁBREGAS GARCÍA, A."Genoese trade network in the southern Iberian peninsula: trade, transmission of technical knowledge and economic interactions", Mediterranean Historical Review, 25/1, 2010, 35-51. http://dx.doi.org/10.1080/09518967.2010.494097 
GAULTIER DALCHÉ, P. "L'usage de cartes marines aux XIV. et XV". siècles", en Spazi, tempi, misure e percorsi nell'Europa del Basso Medioevo. Atti del XXXII Convegno storico internazionale. Todi, 8-11 ottobre 1995, Spoleto, Centro Italiano di Studi sull'Alto Medioevo, 1996, pp. 97-128.

GAULTIER DALCHÉ, P. “Cartes marines, représentation du littoral et perception de l'espace au Moyen Âge. Un état de la question”, en MARTIN, J.M. (ed.) Castrum 7. Zones côtières littorales dans le monde méditerranéen au moyen âge: défense, peuplement, mise en valeur, Madrid, Casa de Velázquez, 2001.

GENSINI, S. (ed.) Europa e Mediterraneo tra Medioevo e prima età moderna: l'osservatorio italiano, Pisa, Centro di Studi sulla Civiltà del Tardo Medioevo, 1992.

GÓMEZ BARCELÓ, J.L. "Tarifa en las crónicas lusas referidas a la costa africana del Estrecho", Al Qantir. Monografías y documentos sobre la Historia de Tarifa, 11, 2011, pp. 133-163.

GONZÁLEZ ARÉVALO, R. "La costa del Reino de Granada en la documentación náutica italiana (siglos XIV-XVI)”, En la España medieval, 31, 2008, pp. 7-36.

—. "La costa del reino de Sevilla en la documentación náutica italiana (siglo XV), en MALPICA CUELLO, A., PEINADO SANTAELLA, A.R.G. y FÁBREGAS GARCÍA, A. (eds.) Historia de Andalucía. VII Coloquio, Granada, 2010, CD-Comunicaciones, pp. 301-317.

-. "Las galeras mercantiles de Florencia en el Reino de Granada en el siglo XV”, Anuario de Estudios Medievales, 41/1, 2011, pp. 125-149. http://dx.doi. org/10.3989/aem.2011.v41.i1.339

—. "Apuntes para una relación velada: la República de Florencia y el Reino de Granada en la Baja Edad Media", Investigaciones de Historia Económica, 8, 2012, pp. 83-93. http://dx.doi.org/10.1016/j.ihe.2011.10.003

GONZÁLEZ JIMÉNEZ, M. "La baja Andalucía en vísperas del descubrimiento", Canarias y América antes del Descubrimiento. La expansión europea. VII Jornadas de Estudios Canarias-América, Santa Cruz de Tenerife, Confederación Española de Cajas de Ahorros, 1985, pp. 109-147.

GONZÁLEZ JIMÉNEZ, M. y BELLO LEÓN, J.M. "El puerto de Sevilla en la Baja Edad Media (siglos XIII-XV), en ABULAFIA, D. y GARÍ, B. (ed.) En las costas del Mediterráneo occidental. Las ciudades de la Península Ibérica y del reino de Mallorca y el comercio mediterráneo en la Edad Media, Barcelona, Omega, 1996, pp. 213-271.

GOZALBES CRAVIOTO, C. "La costa del campo de Gibraltar en los portulanos medievales", Almoraima. Revista de estudios campogibraltareños, 13, 1995, pp. 163-174.

GOZALBES CRAVIOTO, C. "La frontera oriental nazarí en los portulanos medievales", en SEGURA ARTERO, P. (coord.) Actas del Congreso La frontera oriental nazarí como sujeto histórico (S. XIII-XVI). Lorca-Vera, 22 a 24 de noviembre de 1994, Almería, Instituto de Estudios Almerienses-Diputación de Almería, 1997, pp. 451-466. 
—. "La frontera terrestre nazarí en la cartografía medieval", en TORO CEBALLOS, F. y RODRÍGUEZ MOLINA, J. (ed.) II Estudios de Frontera. Actividad y vida en la Frontera. En memoria de don Claudio Sánchez-Albornoz. Congreso celebrado en Alcalá la Real, del 19 al 22 de noviembre de 1997, Jaén, Diputación Provincial de Jaén, 1998, pp. 357-370.

—. "La frontera marítima del occidente malagueño en los documentos geográficos medievales cristianos", en TORO CEBALLOS, F. y RODRÍGUEZ MOLINA, J. (ed.) IV Estudios de Frontera. Historia, tradiciones y leyendas en la frontera. Homenaje a Don Enrique Toral y Peñaranda. Congreso celebrado en Alcalá la Real en noviembre de 2001, Jaén, Diputación Provincial de Jaén, 2002, pp. 247-265.

- "La costa granadina en la cartografía medieval", Qalat. Revista de historia y patrimonio de Motril y la costa de Granada, 4, 2004, pp. 115-129.

—. "Tarifa en la geografía medieval. Fuentes textuales (I)", Aljaranda. Revista de estudios tarifeños, 54, 2004, pp. 7-12.

—. "Tarifa en la geografía medieval. Las fuentes cartográficas (y II)", Aljaranda. Revista de estudios tarifeños, 55, 2004, pp. 5-10.

HEERS, J. "Le commerce des Basques en Méditerranée au XV' siècle (d'après les archives de Gênes)", Bulletin Hispanique, 57, 1955, pp. 292-324. http://dx.doi. org/10.3406/hispa.1955.3441

IGUAL LUIS, D. "Itinerarios comerciales en el espacio meridional mediterráneo de la Baja Edad Media", en Itinerarios medievales e identidad hispánica: XXVII Semana de Estudios Medievales, Estella 17 a 21 de julio de 2000, Pamplona, 2001, pp. 113-158.

LADERO QUESADA, M.Á. "Puertos de Andalucía durante la Baja Edad Media: Sevilla y Málaga", en POLEGGIO, E. (ed.) Città portuali del Mediterraneo. Storia e Archeologia. Atti del Convegno Internazionale di Genova. 1985, Génova, SAGEP Editrice, 1989, pp. 133-140.

LÓPEZ DE COCA CASTAÑER, J.E. "Granada y la ruta de Poniente. El tráfico de frutos secos”, en MALPICA CUELLO, A. (ed.) Navegación maritima del Mediterráneo al Atlántico, Granada 2001, pp. 151-177.

LÓPEZ ESTRADA, F. "Ruy González de Clavijo. La embajada a Tamorlán. Relato del viaje hasta Samarcanda y regreso (1403-1406)", Arbor, CLXXX, 711/712, 2005, pp. 515-535. http://dx.doi.org/10.3989/arbor.2005.i711/712.456

LORENZO SANZ, E. Comercio de España con América en la época de Felipe II, 2 Vols., Valladolid, Diputación Provincial de Valladolid, 1979.

MAIER, J. y SALAS, J. Comisión de Antigüedades de la Real Academia de la Historia. Andalucía. Catálogo e índices, Madrid, Real Academia de la Historia, 2000.

MALLET, M.E. The Florentine galleys in the Fifteenth Century, Oxford, Clarendon Press, 1967.

MALPICA CUELLO, A. "Il traffico commerciale nel mondo mediterraneo occidentale alla fine del Medioevo: il Regno di Granada", en ALBERINI, P. (ed.) Aspetti ed attualità del potere marittimo nel Mediterraneo nei secoli XII-XVI. 
Acta del Convegno di Storia Militare tenuto a Napoli, in Castel dell'Ovo, dal 27 al 29 ottobre 1997, Roma, Ufficio Storico della Marina Militare - Commissione Italiana di Storia Militare, 1999, pp. 351-381.

—. "Poblamiento y vida marítima en el reino de Granada: la pesca y la navegación", en D'ARIENZO, V. y SELVA B. DA (eds.) Pesci, barche, pescatori nell'area mediterranea dal Medioevo all'Età Contemporanea, Milán, Franco Angeli, 2010, pp. 53-67.

MALPICA CUELLO, A. y GÓMEZ BECERRA, A. "La formación de un territorio fronterizo medieval: la costa granadina de la época musulmana a la conquista castellana", en Fronteras. III Coloquio de Arqueología Espacial, Teruel, Colegio Universitario de Teruel. Seminario de Arqueología y Etnografía turolenses, 1989, pp. 241-255.

-. "El poblamiento medieval de la costa oriental granadina", en Actas del III Congreso de Arqueología Medieval Española. Tomo II Comunicaciones, Oviedo, Universidad de Oviedo, 1992, pp. 313-319.

MALPICA CUELLO, A. y FÁBREGAS GARCÍA, A. "La vida marítima y el poblamiento medieval de la costa del Mediterráneo andaluz", en MALPICA CUELLO, A. (ed.) Navegación marítima del Mediterráneo al Atlántico, Granada 2001, pp. 97-148.

—. "Embarcaderos y puertos en la costa del reino de Granada", en FÁBREGAS GARCÍA A. (ed.) Navegación y puertos en época medieval y moderna, Granada, Grupo de investigación "Toponimia, Historia y Arqueología del Reino de Granada", 2012, pp. 75-109.

MARTÍNEZ VALVERDE, C. "Un capitán español del siglo XV. El caballero castellano Don Pero Niño, Conde de Buelna”, Revista de Historia Militar, 57, 1984, pp. 9-53, en concreto pp. 19-39.

—. "La nota marinera en La Crónica de Don Pero Niño", Revista de Historia Naval, 8, 1985, pp. 15-44.

MELIS, F. 'Elenco descrittivo dei porti dell'Europa in un manoscritto fiorentino della fine del Trecento", en FRANGIONI, L. (ed.) I trasporti e le comunicazioni nel Medioevo, Florencia, Le Monnnier, 1984, pp. 69-76.

ORVIETANI BUSCH, S. Medieval mediterranean ports: the Catalan and Tuscan coasts, 1100 to 1235, Leiden, Brill, 2001.

PÉREZ EMBID, F. "Navegación y comercio en el puerto de Sevilla en la Baja Edad Media", Anuario de Estudios Americanos, 25, 1968, pp. 43-94.

PÉREZ MALLAÍNA BUENO, P.E. El hombre frente al mar. Naufragios en la Carrera de Indias durante los siglos XVI y XVII, Sevilla, Universidad de Sevilla, 1996.

PETTI BALBI, G. "Distanze e programmi di viaggio sul mare” en Spazi, tempi, misure e percorsi nell'Europa del Basso Medioevo. Atti del XXXII Convegno storico internazionale. Todi, 8-11 ottobre 1995, Spoleto, Centro Italiano di Studi sull'Alto Medioevo, 1996, pp. 271-295. 
PUJADES I BATALLER, R.J. Les Cartes portolanes. La representació medieval d'una mar solcada, Barcelona, Institut d'Estudis Catalans-Institut Cartogràfic de Catalunya-Institut Europeu de la Mediterrània-Lunwerg, 2007.

RONCIÈRE, M. DE LA y MOLLAT DU JOURDIN M. (eds.) Les portulans. Cartes marines $d u X I I I^{e}$ a a XVII ${ }^{e}$ siècle, Fribourg en Nuithonie, (Suiza), Office du Livre, 1984.

SCHUlTEN, A. Tartessos. Contribución a la Historia más antigua de Occidente, Sevilla, Almuzara, 2006.

TUCCI, U. "La carta nautica”, en BIADENE, S. (ed.) Carte da navigar. Portolani e carte nautiche del Museo Correr 1318-1732, Venecia, Marsilio, 1990, pp. 9-19.

VON DEN BRINCKEN, A-D."Mappe del cielo e della terra: l'orientamento nel basso medioevo", en Spazi, tempi, misure e percorsi nell'Europa del Basso Medioevo. Atti del XXXII Convegno storico internazionale. Todi, 8-11 ottobre 1995, Spoleto, Centro Italiano di Studi sull'Alto Medioevo, 1996, pp. 81-96.

Fecha de recepción del artículo: junio 2013

Fecha de aceptación y versión final: julio 2013 
